\title{
Enhancing seedling production of native species to restore gypsum
}

\section{2 habitats}

Cañadas, E.M. ${ }^{\text {a. }}$ Ballesteros, M. ${ }^{a^{*}}$; Foronda, A. ${ }^{\text {b }}$ N Navarro, F.B. ${ }^{\text {c. }}$ Jiménez, M.N. ${ }^{\text {c }}$;

4 Lorite, $\mathrm{J}^{\mathrm{a}}$.

a Department of Botany, Faculty of Sciences, University of Granada, Granada, Spain.

6 Avda. Fuentenueva, s/n. Granada, 18071, Spain.

${ }^{\mathrm{b}}$ Instituto Pirenaico de Ecología (CSIC), Avda. Montañana, 1005, P.O. Box 13034,

8 50080, Zaragoza, Spain.

${ }^{c}$ Agroecosystems Sustainability Group (AGROECOSOST), IFAPA Centro Camino de

10 Purchil (Junta de Andalucía), Camino de Purchil s/no, 18004 Granada (Spain).

$12{ }^{*}$ Corresponding author:

Miguel Ballesteros

14 Departamento de Botánica

Facultad de Ciencias, Universidad de Granada

16 E-18071, Granada (Spain)

e-mail: miguelballesterosjimenez@gmail.com

18

\section{ABSTRACT}

20 Gypsum habitats are widespread globally and are important for biological conservation. Nevertheless, they are often affected by human disturbances and thus require

22 restoration. Sowing and planting have shown positive results, but these actions are usually limited by the lack of native plant material in commercial nurseries, and very

24 little information is available on the propagation of these species. We address this issue from the hypothesis that gypsum added to a standard nursery growing medium

26 (peat) can improve seedling performance of gypsum species and, therefore, optimise the seedling production for outplanting purposes. We test the effect of gypsum on

28 emergence, survival, and growth of nine native plant species, including gypsophiles (exclusive to gypsum) and gypsovags (non-exclusive to gypsum). We used four

30 treatments according to the proportions, in weight, of gypsum:standard peat, i.e. high-g (50:50), medium-g (25:75), low-g (10:90), and standard-p (0:100).

32 Our results showed that the gypsum treatments especially benefited the emergence stage, gypsophiles as group, and Ononis tridentata as a taxon. In

34 particular, the gypsum treatments enhanced emergence of seven species, survival of three species, and growth of two gypsophiles, while the use of the standard peat

36 favoured only the emergence or growth of three gypsovags. Improving emergence and survival in the nursery can provide a reduction of costs associated with seed

38 harvesting, watering, and space, while enlarging seedlings can favour the establishment of individuals after outplanting. Thus, we suggest adding gypsum to a 
40 standard growing medium for propagating seedlings in species from gypsum habitats, thereby potentially cutting the costs of restoring such habitats. Our assessment enables

42 us to provide particular advice by species. In general, we recommend using between 25 and $50 \%$ of gypsum to propagate gypsophiles, and between 0 and $10 \%$ for

44 gypsovags. The results can benefit not only the production of widely distributed species commonly affected by gypsum quarrying, but also of narrow and threatened endemic

46 species that require particularly efficient use of their seeds. In addition, our study shows the importance of using an appropriate growing medium to propagate plants

48 characteristic of special soils such as gypsum soils.

50 Keywords: growing medium, gypsum treatment, gypsophiles, gypsovags, gypsum species, seedling production

\section{Introduction}

54 Gypsum soils are widespread, with more than100 million ha worldwide, almost exclusively in arid and semi-arid regions (Boyadgiev and Verheye, 1996). These soils

56 host very rare and narrow endemic flora that includes many endangered species, making them priority sites for biological conservation (Anonymous, 1992; Parsons,

58 1976; Mota et al., 2011; Sosa and De-Nova, 2012). However, gypsum habitats are often impacted by human disturbances such as quarrying, ploughing or grazing (Al-

60 Harthi, 2001; Mota et al., 2004; Pulido-Bosch et al., 2004; Pueyo and Alados, 2007; Ballesteros et al., 2013). Therefore, recovery plans for these environments need to be

62 addressed, and proactive measures need to be considered (Ballesteros et al., 2012, 2014), because natural succession has proved inefficient over the short term (Mota et

64 al. 2003, 2004; Dana and Mota, 2006).

The recovery of gypsum areas has been satisfactorily approached through

66 hydroseeding (Matesanz and Valladares, 2007), sowing (Ballesteros et al., 2012) or planting (Sharma et al., 2001; Blignaut and Milton, 2005; Ballesteros et al., 2014).

68 Nonetheless, one of the main problems in restoring these environments is the lack of native plant material (seeds and seedlings), even though some studies report that this

70 is a key factor (e.g. Matesanz et al., 2006). Thus, despite the successful use of planting as a restoration technique for gypsum habitats (e.g. Ballesteros et al., 2014), it is

72 difficult to find seedlings of native species for gypsum substrates (gypsum species, hereafter) in commercial or public nurseries. In fact, little information is available for

74 producing these native species. In addition, many of the gypsum species are narrowly 
endemic and/or endangered species and require specific harvesting efforts and

76 efficient use of their seeds, for which the development of effective propagation methods constitutes a priority. In this sense, testing methods are required in order to enhance

78 the emergence and survival of seedlings. Moreover, promoting early growth of seedlings during the nursery phase is particularly relevant for better outplanting

80 performance (Kormanik, 1986; Thompson and Schultz, 1995; Jacobs et al., 2005).

In this context, we studied seedling production in gypsum species, starting from

82 the premise that most of these are highly specialized in gypsum substrates. In this regard, several field experiments have demonstrated that the selection of a suitable

84 substrate, composed mainly of native gypsum, effectively contributes to the success in sowing and planting (Ballesteros et al., 2013, 2014). Also, other experiments evidence

86 that the presence of gypsum in the growth medium can be a key factor for gypsum species at the initial stages (e.g. Escudero et al., 1999, 2000; Cañadas et al., 2014),

88 but this has never been verified for seedling production. Thus, we hypothesised that the addition of gypsum to a standard growing medium could enhance seedling

90 performance and, therefore, the production of native plants in the recovery of gypsum habitats. To test this, we designed a manipulative factorial experiment to produce

92 seedlings of nine gypsum species in a growth chamber, adding different gypsum proportions to a nursery growing medium commonly used for plant production. We

94 monitored three key stages in plant production: emergence, survival, and early growth. Therefore, in this study, we determine whether gypsum treatments affect seedling

96 performance, with the final aim of gaining insight into the propagation of gypsum species for habitat-restoration purposes.

98

\section{Materials and methods}

100 2.1. Target species and seed collection

Nine characteristic species of the EU priority habitat "Iberian gypsum vegetation,

102 Gypsophiletalia" (Anonymous, 1992) were selected, including gypsophile (i.e. restricted to gypsum soils) and gypsovag plant species (i.e. occurring commonly on

104 both gypsum and non-gypsum substrates; sensu Meyer, 1986). The gypsophiles were Helianthemum squamatum (L.) Dum. Cours. (Cistaceae), Lepidium subulatum L.

106 (Brassicaceae), Gypsophila struthium L. subsp. struthium (Caryophyllaceae), Ononis tridentata L. subsp. crassifolia (Dufour ex Boiss.) Nyman (Leguminosae), and Santolina

108 viscosa Lag. (Asteraceae). The first three gypsophiles are widely distributed in gypsum outcrops in the Iberian Peninsula and some localities in North Africa, and the last two 
110 arenarrow endemic species restricted to specific gypsum outcrops in south-eastern Iberian Peninsula and considered threatened (Vulnerable; Ballesteros et al., 2013). The

112 four remaining species were gypsovags: Helianthemum syriacum (Jacq.) Dum. Cours. (Cistaceae), Frankenia thymifolia Desf. (Frankeniaceae), Rosmarinus officinalis $L$.

114 (Lamiaceae), Stipa tenacissima L. (Poaceae), all with a Mediterranean distribution (see Blanca et al., 2009 and Mota et al., 2011 for further details on the selected species).

116 Seeds were collected in gypsum outcrops in south-eastern Spain $\left(37.17^{\circ} \mathrm{N}\right.$, $2.84^{\circ} \mathrm{W}$ ), under a semiarid and dry Mediterranean climate (rainfall ranging from 200 to

$118500 \mathrm{~mm}$ ). Seeds were harvested from at least 50 individuals per species in natural populations. Subsequently, seeds were cleaned, discarding any visually malformed

120 seed, and stored in darkness in paper bags under ambient conditions (c. $20^{\circ} \mathrm{C}$ and c. $30 \%$ relative humidity) until the experiment started.

\subsection{Experimental design}

124 We performed a manipulative experiment in a full factorial design including two factors: species (specified above) and gypsum treatments. To apply gypsum

126 treatments, we prepared four different mixtures of standard nursery growing medium, i.e. peat (composition: organic matter $=85.4 \%, \mathrm{pH}=6-7, \mathrm{~N}=260 \mathrm{mg} / \mathrm{kg}, \mathrm{P}=389 \mathrm{mg} / \mathrm{kg}$,

$128 \mathrm{~K}=2000 \mathrm{mg} / \mathrm{kg}, \mathrm{Mg}=678 \mathrm{mg} / \mathrm{kg}, \mathrm{Fe}=15 \mathrm{mg} / \mathrm{kg})$ and powdered gypsum $\left(\mathrm{CaSO}_{4} \cdot 2 \mathrm{H}_{2} \mathrm{O}\right)$. According to the gypsum:standard peat in weight, we established four treatments,

130 called: high-g (50G:50S), medium-g (25G:75S), low-g (10G:90S), and standard-p, (0G:100S, which represents the control treatment, because it is customarily used to

132 propagate nursery plants).

We filled completely 450 pots of $250 \mathrm{~cm}^{3}(6 \mathrm{~cm} \times 5.6 \mathrm{~cm} \times 8 \mathrm{~cm})$ with each gypsum

134 treatment (50 pots per species), and then in each pot 10 seeds of the same species were sown. Thus, a total of 1800 pots were placed, in a completely randomized array

136 (9 species $\times 4$ gypsum treatments $\times 50$ replicates), in a growth chamber on three aluminium tables equipped with controlled spray-irrigation systems set to water every

138 three days. The chamber was kept at $25^{\circ} \mathrm{C}\left(\mathrm{ETN}^{\circledR}\right.$ thermostat, Carrier España, S.L.), under $14 \mathrm{~h}$ light/ $10 \mathrm{~h}$ darkness (FAEBER ${ }^{\circledR}$ lighting system, TIGER $^{\circledR}$, including 400w

140 E40/ES OSRAM ${ }^{\circledR}$ lights, and a MicroRex D11 timer, LEXIC, LEGRAND ${ }^{\circledR}$ ), reproducing favourable conditions for optimal plant development in the habitat (photoperiod and

142 temperature from June to September). 
Pots were monitored for 21 weeks recording weekly emergence and survival. We

146 visually checked cotyledon protrusion for emergence and marked the first seedling to emerge in each pot, or a randomly selected one if several seedlings emerged the same

148 week (first individual, hereafter), for survival monitoring. Following the same criteria, a second seedling was marked to ensure that enough individuals were available to

150 assess growth, in case of early death of the first individual. When each pot had two seedlings, new emerging plants were immediately removed after recording emergence.

152 The second marked seedling in each pot was also removed after 4 weeks if the first individual survived, in order to avoid competition between seedlings.

154 After 21 weeks, the seedlings were harvested and washed with distilled water. Subsequently, we separated the shoots from roots and dried them in an oven $\left(70^{\circ} \mathrm{C}\right.$ for

$15648 \mathrm{~h})$. We weighed the samples in a precision scale $(0.0001 \mathrm{~g})$, after stabilization at room temperature, recording shoot and root biomass separately. These data were used

158 to evaluate gypsum effects on growth.

\subsection{Data analyses}

162 The effect by species of gypsum treatments on emergence (measured as the percentage of emerged seedlings and as the time to emergence of the first individual)

164 and growth (in terms of shoot and root biomass) was modelled by fitting generalized linear models (GLMs). Emergence was modelled by specifying a binomial error

166 distribution and logit-link function for the percentage of emerged seedlings, and a poisson error distribution and a log-link function for the time to emergence of the first

168 individual. The growth data were submitted to logarithmic transformation. To assess the effect of the different gypsum treatments on seedling survival, we fit Cox proportional

170 hazard models by species as well as the Kaplan-Meier function to plot differences in survival among treatments (R "survival" package; Therneau, 2013). Despite that pots

172 were monitored for 21 weeks, only individuals that emerged before the ninth week were used to assess the time to death in the survival analysis, ensuring an individual

174 monitoring of 12 weeks at least (first week being the week of emergence). Also the biomass of the surviving individuals emerged before the ninth week was used to 176 evaluate gypsum effects on growth.

\section{3. Results}

\subsection{Emergence}


180 Gypsum proved to have a significant effect on emergence for most species, with at least one gypsum treatment being positive compared to the standard-p for all

182 gypsophiles and two gypsovags (Tables 1 and 2, Appendix A; Table A.1). In particular, emergence of the two threatened endemic species (O. tridentata and $S$. viscosa) was

184 significantly higher in any of the gypsum treatment than in standard-p. The highest emergence rate of $G$. struthium was recorded in 25G:75S while high-g negatively

186 influenced emergence. Moreover, the highest number of emerged seeds was found in high-g for F. thymifolia, 25G:75S for L. subulatum, and low-g for $H$. squamatum and $H$.

188 syriacum. Standard-p was a better treatment for emergence only in the case of $S$. tenacissima and $R$. officinalis. Gypsum treatments had no effect on the emergence

190 time of the first individual in any case (Appendix A: Table A.2).

\section{3.2. Survival}

Gypsum treatments positively affected the survival of three species after 12 weeks

194 (Tables 1 and 2, Fig. 1, Appendix A: Table A.3). In particular, the survival of O. tridentata subsp. crassifolia and F. thymifolia seedlings proved significantly higher with any of the

196 gypsum treatments than in standard-p. Thus, O. tridentata survival rose from $20.7 \%$ in standard-p to $83.3 \%$ in the high-g. F. thymifolia survival was $26.2 \%$ in standard-p but

198 increased to $58.0 \%$ in the low-g. The highest survival values for $H$. squamatum seedlings were recorded in high-g (78.0\%), while the lowest survival $(42.6 \%)$ was in

200 standard-p. Also, significant differences among treatments were found for L. subulatum, although differences between the highest survival in low-g (41.9\%) and standard-p

202 (25\%) were not significant. For the remaining five taxa, the survival was high in both standard-p and gypsum treatments (higher than $72.9 \%$ in all cases), with no significant

204 effects among treatments.

\section{3.3. Early growth}

Gypsum had a significant effect on seedling growth for some of the species (Tables

2081 and 2, Appendix A: Table A.4). In particular, we found no negative effects of gypsum on early growth in plants of the gypsophile group, except for S. viscosa at high-g. By

210 contrast, gypsum had a significantly positive effect on $O$. tridentata growth, with the effect of high-g being particularly positive on shoot and root. Shoot growth of $H$.

212 squamatum was also significantly higher in all gypsum treatments than in thestandardp. Concerning the gypsovag group, no significant positive effects of gypsum were

214 found. On the contrary, the effect of gypsum treatments on $F$. thymifolia growth was 
negative. $H$. syriacum growth was significantly lower at high-g than in standard-p, but

216 medium and low-g did not negatively affect growth. In addition, medium-g and high-g reduced root growth of $R$. officinalis compared to standard-p, and no significant

218 response was recorded for S. tenacissima.

220 Table 1. Summary of the results by stages, species, and treatments. Treatments according to weight proportions of gypsum:standard growing medium; High-g

222 (50G:50S), Medium-g (25G:75S), Low-g (10G:90S), Standard-p (0G:100S).

\begin{tabular}{|c|c|c|c|c|c|}
\hline Species & Gypsum level & $\begin{array}{c}\text { Mean } \\
\text { Emergence } \\
(\% \pm \mathrm{SE})\end{array}$ & $\begin{array}{c}\text { Survival } \\
(\%)\end{array}$ & $\begin{array}{c}\text { Mean shoot } \\
\text { biomass } \\
(\mathrm{mg} \pm \mathrm{SE})\end{array}$ & $\begin{array}{c}\text { Mean root } \\
\text { biomass } \\
\text { (mg } \pm \text { SE) }\end{array}$ \\
\hline \multirow{4}{*}{$\begin{array}{l}\text { Ononis tridentata L. } \\
\text { subsp. crassifolia }\end{array}$} & Standard-p & $12.6 \pm 1.7$ & 20.7 & $18.3 \pm 1.8$ & $7.9 \pm 0.9$ \\
\hline & Low-g & $17.1 \pm 2.2$ & 51.6 & $32.1 \pm 1.8$ & $17.3 \pm 1.2$ \\
\hline & Medium-g & $17.3 \pm 1.9$ & 76.3 & $36.1 \pm 7.1$ & $18.1 \pm 3.5$ \\
\hline & High-g & $17.4 \pm 1.4$ & 83.3 & $147.8 \pm 32.5$ & $43.5 \pm 7.2$ \\
\hline \multirow{4}{*}{$\begin{array}{l}\text { Gypsophila struthium } \\
\text { subsp. struthium }\end{array}$} & Standard-p & $54.4 \pm 3.2$ & 81.6 & $128.6 \pm 16.0$ & $28.1 \pm 4.0$ \\
\hline & Low-g & $54.0 \pm 2.6$ & 86 & $125.1 \pm 15.8$ & $24.1 \pm 3.4$ \\
\hline & Medium-g & $56.6 \pm 2.5$ & 84 & $119 \pm 16.7$ & $30.0 \pm 4.8$ \\
\hline & High-g & $41.8 \pm 3.4$ & 72.9 & $123.9 \pm 14.5$ & $29.2 \pm 3.1$ \\
\hline \multirow{4}{*}{$\begin{array}{l}\text { Helianthemum } \\
\text { squamatum }\end{array}$} & Standard-p & $44.8 \pm 3.0$ & 42.6 & $3.5 \pm 0.4$ & $2.4 \pm 0.3$ \\
\hline & Low-g & $48.8 \pm 2.2$ & 42.9 & $4.4 \pm 0.4$ & $1.9 \pm 0.2$ \\
\hline & Medium-g & $46.8 \pm 2.4$ & 60 & $4.1 \pm 0.3$ & $2.3 \pm 0.2$ \\
\hline & High-g & $47.4 \pm 3.0$ & 78 & $4.5 \pm 0.4$ & $1.8 \pm 0.2$ \\
\hline \multirow{4}{*}{ Lepidium subulatum } & Standard-p & $22.6 \pm 2.1$ & 25 & $30.7 \pm 11.4$ & $4.9 \pm 1.5$ \\
\hline & Low-g & $15.8 \pm 2.3$ & 41.9 & $10.8 \pm 3.2$ & $3.1 \pm 0.9$ \\
\hline & Medium-g & $29.4 \pm 3.4$ & 24.4 & $18.9 \pm 10.4$ & $3.4 \pm 1.8$ \\
\hline & High-g & $22.4 \pm 2.3$ & 16.7 & $5.8 \pm 1.0$ & $2.9 \pm 0.7$ \\
\hline \multirow{4}{*}{ Santolina viscosa } & Standard-p & $41.2 \pm 2.6$ & 95.9 & $15.3 \pm 2.5$ & $7.3 \pm 1.2$ \\
\hline & Low-g & $43.8 \pm 3.1$ & 97.9 & $11.4 \pm 2.0$ & $5.8 \pm 0.8$ \\
\hline & Medium-g & $60.0 \pm 3.7$ & 95.9 & $13.8 \pm 2.3$ & $6.0 \pm 0.7$ \\
\hline & High-g & $56.6 \pm 3.0$ & 94.0 & $11.4 \pm 2.3$ & $4.3 \pm 0.6$ \\
\hline \multirow{4}{*}{$\begin{array}{l}\text { Helianthemum } \\
\text { syriacum }\end{array}$} & Standard-p & $78.6 \pm 3.1$ & 91.8 & $5.0 \pm 0.1$ & $2.4 \pm 0.5$ \\
\hline & Low-g & $81.8 \pm 1.9$ & 80 & $7.0 \pm 0.0$ & $2.3 \pm 0.2$ \\
\hline & Medium-g & $78.0 \pm 2.9$ & 91.8 & $7.1 \pm 0.3$ & $2.9 \pm 0.3$ \\
\hline & High-g & $72.4 \pm 3.1$ & 82 & $3.8 \pm 0.1$ & $1.2 \pm 0.1$ \\
\hline \multirow{4}{*}{ Frankenia thymifolia } & Standard-p & $30.0 \pm 3.1$ & 26.2 & $11.9 \pm 3.2$ & $5.9 \pm 1.1$ \\
\hline & Low-g & $47.2 \pm 2.6$ & 58.8 & $7.9 \pm 2.2$ & $1.7 \pm 0.4$ \\
\hline & Medium-g & $30.0 \pm 2.9$ & 38.6 & $1.4 \pm 0.4$ & $0.5 \pm 0.1$ \\
\hline & High-g & $57.8 \pm 2.9$ & 44.9 & $0.7 \pm 0.2$ & $0.3 \pm 0.1$ \\
\hline \multirow{4}{*}{ Rosmarinus officinalis } & Standard-p & $51.8 \pm 3.2$ & 91.8 & $32.5 \pm 5.3$ & $17.3 \pm 1.7$ \\
\hline & Low-g & $44.0 \pm 2.9$ & 100.0 & $25.1 \pm 3.7$ & $15.6 \pm 1.8$ \\
\hline & Medium-g & $38.0 \pm 3.3$ & 97.8 & $26.1 \pm 5.4$ & $13.7 \pm 1.5$ \\
\hline & High-g & $50.0 \pm 3.9$ & 93.0 & $21.8 \pm 2.4$ & $11.5 \pm 0.9$ \\
\hline \multirow{4}{*}{ Stipa tenacissima } & Standard-p & $22.8 \pm 2.6$ & 93.2 & $25.6 \pm 3.0$ & $13.8 \pm 1.8$ \\
\hline & Low-g & $15.2 \pm 2.0$ & 94.3 & $27.6 \pm 2.6$ & $14.6 \pm 1.3$ \\
\hline & Medium-g & $11.2 \pm 2.0$ & 100.0 & $29.0 \pm 3.8$ & $16.0 \pm 3.1$ \\
\hline & High-g & $15.8 \pm 2.9$ & 93.3 & $24.3 \pm 1.9$ & $13.3 \pm 1.3$ \\
\hline
\end{tabular}


Figure 1. Kaplan-Meier survival curves representing species survival over 12

228 weeks for each treatment. Only the plots for species in which the treatment had significant effect on the survival are shown.
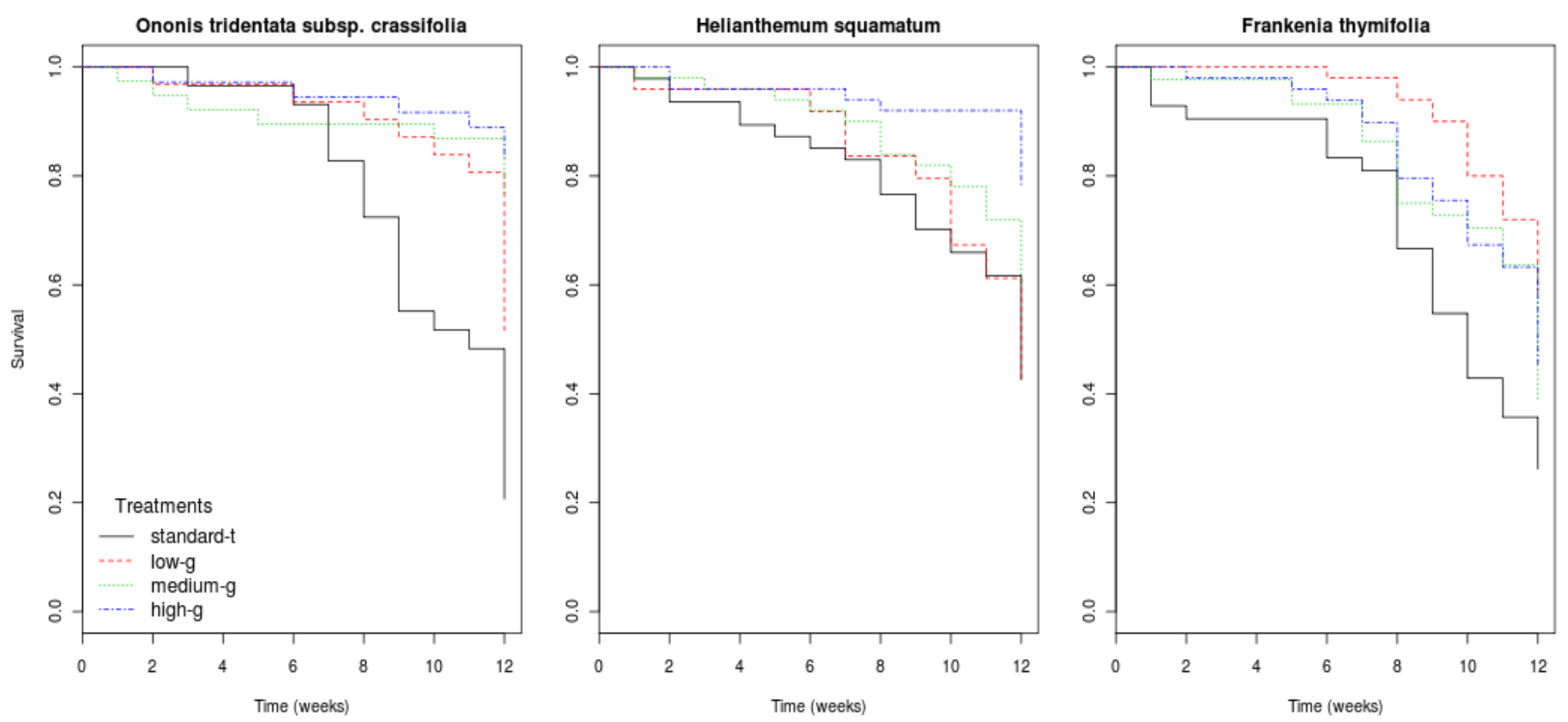

Table 2. Summary of gypsum treatment effects on emergence, survival, shoot 232 growth and root growth by species. Treatments according to weight proportion of gypsum:standard growing medium; H/High-g (50:50), M/Medium-g (25:75), L/Low-g

234 (10:90), standard-p (0:100). Sign of gypsum treatment effect compared to standard-p: (+) positive, (-) negative, (ns) no significant effects, according to GLMs and Cox

236 proportional hazard model (see Appendix A for additional information). ( $\left.{ }^{\mathrm{a}}\right)$ : The number of stages (emergence, survival, growth) favoured by the most beneficial treatment appear in brackets; $\left({ }^{*}\right)$ indicate marginally significant effects.

\begin{tabular}{|c|c|c|c|c|c|c|c|c|c|c|c|c|c|}
\hline & \multicolumn{3}{|c|}{ Emergence } & \multicolumn{3}{|c|}{ Survival } & \multicolumn{3}{|c|}{$\begin{array}{c}\text { Shoot } \\
\text { growth }\end{array}$} & \multicolumn{3}{|c|}{$\begin{array}{c}\text { Root } \\
\text { growth }\end{array}$} & \multirow{2}{*}{$\begin{array}{l}\text { Most beneficia } \\
\text { treatment for } \\
\text { growing }^{\mathrm{a}}\end{array}$} \\
\hline & $\mathbf{L}$ & $\mathbf{M}$ & $\mathbf{H}$ & $\mathbf{L}$ & M & $\mathbf{H}$ & $\mathbf{L}$ & M & $\mathbf{H}$ & $\mathbf{L}$ & $\mathbf{M}$ & $\mathbf{H}$ & \\
\hline O. tridentata c. & + & + & + & + & + & + & + & + & + & $t$ & + & + & High-g (3) \\
\hline H. squamatum & + & + & + & ns & $+{ }^{*}$ & + & + & + & + & ns & ns & ns & High-g (3) \\
\hline G. struthium S. & ns & + & - & ns & ns & ns & ns & ns & ns & ns & ns & ns & Medium-g (1) \\
\hline L. subulatum & - & + & ns & ns & ns & ns & ns & ns & ns & ns & ns & ns & Medium-g(1) \\
\hline S. viscosa & $+^{*}$ & + & + & ns & ns & ns & ns & ns & - & ns & ns & - & Medium-g (1) \\
\hline H. syriacum & + & ns & - & ns & ns & ns & ns & ns & - & ns & ns & - & Low-g (1) \\
\hline F. thymifolia & + & ns & + & + & $+{ }^{*}$ & + & - & - & - & - & - & - & Low-g (2) \\
\hline R. officinalis & - & - & ${ }^{*}$ & ns & ns & ns & ns & ns & ns & ns & - & - & Standard-p (1) \\
\hline
\end{tabular}


S. tenacissima - $\quad-\quad$ ns ns ns ns ns ns ns ns ns Standard-p (1)

\section{Discussion}

246 Our results reveal that gypsum treatments had positive effects on seedlings for most of the target species at some of the stages studied (i.e. emergence, survival

248 and/or growth). Gypsum treatments especially favoured the performance of gypsophiles, while the use of standard peat without gypsum benefited only emergence 250 or growth of three gypsovags (Table 2).

We found that emergence was the most affected stage, when gypsum positively

252 influenced most of the species (seven of nine) while the standard treatment favoured only the emergence of two gypsovags. Our results on emergence partially agree with a

254 previous germination study (Cañadas et al., 2014), and the differences could be related to substrate, germination chamber, and type of gypsum treatments (e.g. Boeken et al.,

256 2004; Golle et al., 2010). Regarding survival, we found that gypsum treatments favoured three species while no species benefited by growing in the standard peat.

258 Moreover, gypsum also enhanced growth of two gypsophiles but did not bolster the growth of any gypsovag. Our results are somewhat different to those showed by

260 Boukhris and Lossaint (1975), who stated that gypsophiles grew equally well in soils with high sulphur content and in commercial soils; but it was a different study because

262 sulphur content is just one of the features of gypsum.

Overall, more positive effects of gypsum were found for gypsophiles than for

264 gypsovags, suggesting that effects depend not only on the growing medium properties but also on the ecological strategies of species. In line with our results, different

266 ecological strategies in gypsum species have been linked to plant groups in some studies (i.e. widely distributed gypsophiles, narrowly distributed gypsophiles, and

268 gypsovags; e.g. Palacio et al., 2007; Cañadas et al., 2014; Escudero et al., 2014; Palacio et al., 2014). In particular, Palacio et al., (2014) evidenced plant specialization

270 mechanism to gypsum in gypsophiles, which showed the widespread presence of gypsum and calcium oxalate crystals and the accumulation of sulphates in organic

272 molecules, while gypsovags seem to be stress tolerant plants that tightly regulate the uptake of $\mathrm{S}$ and $\mathrm{Ca}$ by their roots. These specialization and adaptative mechanism to gypsum could explain a better performance of studied species in gypsum treatments. 
However, the functioning of gypsum species and the habitat that they occupy is still not

276 fully understood and further studies are needed in this regard (Escudero et al., 2014).

Certainly, our results revealed that the addition of gypsum to a standard nursery

278 growing medium is advantageous to seedling performance and, therefore, to optimise production of native species for gypsum-habitat restoration. This is an important finding

280 regardless of the specific causes, which could become a relevant theme for a separate study. In seedling production, the harvested seeds can provide greater efficiency if

282 emergence and survival are optimised, which could reduce harvesting costs or problems arising from low availability of seeds. Also other inputs influencing costs of

284 plant production, and therefore of restoration plans, such as space and water could be optimised. In this respect, at least one of the gypsum treatments favoured emergence

286 in seven of the nine species studied as well as the survival in three species, whereas the standard treatment benefited only the emergence of two gypsovag species and did

288 not enhance the survival of any of the species.

In addition, the seedlings of two species (O. tridentata and $H$. squamatum) were

290 larger in all of the gypsum treatments than in standard-p. Size is a reliable, easy-to-use indicator of seedling quality (Jacobs et al., 2005; Renou-Wilson et al., 2008; Oliet et al.,

292 2009; Close et al., 2010), and using high-quality seedlings is a key factor in establishing plantations (e.g. Wilson and Jacobs 2006), especially under arid

294 Mediterranean conditions (e.g. Cortina et al., 2006; Oliet et al., 2009; Jiménez et al., 2014). Despite that this issue has not been resolved for gypsophile seedlings in

296 planting, under natural conditions the largest seedlings of $H$. squamatum and $L$. subulatum also showed the highest survival rate (Escudero et al., 1999, 2000).

298 Therefore, the field performance after the planting of species such as $O$. tridentata and $H$. squamatum could be enhanced if seedlings are grown after adding gypsum to the

300 standard peat. However, seedling performance in field also depended on other factors such as shoot-to-root ratio, stem diameter, and physiological condition of seedlings (e.g

302 Ritchie et al., 2010)

Results by species enable us to provide particular suggestions to optimise the 304 production of each species (Table 2), which is feasible because it involves only the addition of gypsum to a standard nursery growing medium in the initial phase. The

306 results are particularly relevant for the two endemic and threatened taxa studied, i.e. $O$. tridentata subsp. crassifolia and S. viscosa. Gypsum treatments enhanced the

308 emergence of both species, which is especially important for $O$. tridentata, the seeds of which are often difficult to harvest, highly depredated (Ballesteros et al., 2013), and

310 have low germination rates (Cañadas et al., 2014). Furthermore, emerged seedlings of 
O. tridentata showed higher survival rates in medium-g and high-g, and all gypsum

312 treatments favoured seedling growth in comparison to standard-p, the high-g treatment being particularly favourable. In addition, emergence, survival, and growth for the

314 gypsophile $H$. squamatum were also benefited by the high-g. This result agrees with Escudero et al. (1999), who found that $H$. squamatum was able to grow in the field on a

316 wide variety of soils, although its survival rate and growth were higher on genuine gypsum soils. We also found that medium-g favoured the emergence of $L$. subulatum

318 and $G$ struthium, while other stages were not significantly influenced by gypsum. Thus, we suggest sowing $O$. tridentata subsp. crassifolia and $H$. squamatum using the high-g

320 (because it benefits the three stages studied), and S. viscosa, G struthium, and $L$. subulatum using the medium-g (because it favoured emergence). Regarding the

322 gypsovag group, seedling production of $F$. thymifolia and $H$. syriacum could be also enhanced using the low-g, because it favoured their emergence and $F$. thymifolia

324 survival. Conversely, for species such as $R$. officinalis and $S$. tenacissima, we suggest using a non-amended standard growing medium, without adding gypsum, because it

326 yielded the best emergence.

Our study shows the importance of selecting an appropriate growing medium to

328 propagate plants characteristic of special soils such as gypsum soils. (associated to specific substrates, as reported for copper, serpentine or Ballesteros et al., 2012;

330 O'Dell and Claassen, 2009; Whiting et al., 2004).this context, the selection of starting mate-rials determines the success of restoration processes (Bradshaw,2000), and is

332 particularly decisive for the recovery of singular flora

\section{5. Conclusions}

Our results reveal that the addition of gypsum to a standard nursery growing

336 medium benefited seedling performance in most of the tested species. This constitutes the first approach to the testing of methods to produce seedlings of gypsum species for

338 restoration purposes. In particular, the gypsum treatments especially benefited emergence as a stage, gypsophiles as a plant group, and $O$. tridentata as a taxon.

340 Altogether, seven of nine species benefited from the gypsum treatments to improve emergence and/or survival, implying better use of the available seeds and a reduction

342 in costs associated with seed harvesting, watering or space. Furthermore, larger seedlings of two species resulted after using gypsum, which could favour the

344 establishment in the field of individuals after outplanting. Thus, we suggest applying gypsum treatments to improve efficiency in the propagation of gypsum species, which

346 would cut the costs of gypsum-habitat restoration plans. The results regarding plant 
performance by species enable us to provide particular suggestions to optimise the

348 cultivation of each species, which are feasible to apply. In general, we recommend using a standard growing medium mixed with $25-50 \%$ of gypsum by weight to

350 propagate gypsophiles, while using solely the standard growing medium, or $0-10 \%$ of gypsum, to propagate gypsovags. The results may benefit not only the production of

352 widely distributed species commonly affected by gypsum quarrying, but also narrow and threatened endemic species such as $O$. tridentata subsp. crassifolia, which require

354 a particularly efficient use of its seeds. Finally, our study shows the importance of using an appropriate growing medium to propagate plants characteristic of special soils such 356 as gypsum soils, which could be also applied to growing plant species to restore other particular habitats.

\section{Acknowledgements}

360 This study was carried out in the framework of the research projects "Study of the ecological basis for restoration of gypsum vegetation in the Ventas de Huelma and

362 Escúzar quarries", and "Development of techniques for the ecological restoration of gypsum habitats, P11-RNM-7061" funded respectively by KNAUF GmbH Branch Spain

364 and the Consejería de Innovación Ciencia y Empresa, Junta de Andalucía. M. Ballesteros holds a research grant from Junta de Andalucía, Proyectos de Excelencia

366 (P11-RNM-7061) and M.N. Jiménez was sponsored by the Operating Programme of the European Social Found for Andalucía (2007-2013). We would like to thank David

368 Nesbitt for linguistic advice.

\section{5. REFERENCES}

372 Al-Harthi, A.A. 2001. Environmental impacts of the gypsum mining operation at Maqna area, Tabuk, Saudi Arabia. Environmental Geology 41: 209-218.

374 Anonymous. 1992. Council Directive 92/43/EEC on the conservation of natural habitats and of wild fauna and flora. European Commission's Directorate-General for the

376 Environment, Brussels. Belgium.

Ballesteros, M., Cañadas, E.M., Foronda, A., Fernández-Ondoño, E., Peñas, J., Lorite, 378 J. 2012. Vegetation recovery of gypsum quarries: short-term sowing response to different soil treatments. Applied Vegetation Science 15: 187-197. 
380 Ballesteros, M., Cañadas, E.M., Foronda, A., Peñas, J., Valle, F., Lorite, J. 2014. Central role of bedding materials for gypsum-quarry restoration: an experimental planting of gypsophile species. Ecological Engineering 70: 470-476.

Ballesteros, M., Foronda, A., Cañadas, E.M., Peñas, J., Lorite, J. 2013. Conservation

Blanca, G., Cabezudo, B., Cueto, M., Fernández-López, C., Morales-Torres, C. (Eds.). 2009. Flora Vascular de Andalucía Oriental, 4 Vols. Consejería de Medio

Blignaut, A., Milton, S.J. 2005. Effects of multispecies clumping on survival of three succulent plant species translocated onto mine spoil in the Succulent Karoo Desert, South Africa. Restoration Ecology 13: 15-19.

Boeken, B., Ariza, C., Gutterman, Y., Zaady, E. 2004. Environmental factors affecting dispersal, germination and distribution of Stipa capensis in the Negev Desert,

Boukhris, M., Lossaint, P. 1975. Aspects ecologiques de la nutrition minerale de plantes gypsicoles di Tunisie. Revue d'Ecologie et de Biologie du Sol 12: 329348.

Boyadgiev, T.G.,Verheye, W.H. 1996.Contribution to a utilitarian classification of gypsiferous soil. Geoderma 74: 321-338.

Cañadas, E.M., Ballesteros, M., Valle, F., Lorite, J. 2014. Does gypsum influence seed germination? Turkish Journal of Botany 38: 141-147.

402 Close, D.C., Paterson, S., Corkrey, R., McArthur, C. 2010. Influences of seedling size, container type and mammal browsing on the establishment of Eucalyptus globulus in plantation forestry. New Forests 39: 105-115.

Cortina, J., Peñuelas, J.L., Puértolas, J., Savé, R., Vilagrosa, A. 2006. Calidad de planta forestal para la restauración en ambientes mediterráneos. Organismo Autónomo Parques Nacionales, Ministerio de Medio Ambiente. Madrid. Spain.

408 Dana, E.D., Mota, J.F. 2006. Vegetation and soil recovery on gypsum outcrops in semiarid Spain. Journal of Arid Environments 65: 444-459.

410 Escudero, A., Iriondo, J.M., Olano, J.M., Rubio, A., Somolinos, R.C., 2000. Factors affecting establishment of a gypsophyte: the case of Lepidium subulatum (Brassicaceae). American Journal of Botany 87: 861-871.

Escudero, A., Palacio, S., Maestre, F.T., Luzuriaga, A.L. 2014. Plant life on gypsum: a review of its multiple facets. Biological Reviews. DOI: 10.1111/brv.12092 
Escudero, A., Somolinos, R.C., Olano, J.M., Rubio, A. 1999. Factors controlling the establishment of Helianthemum squamatum, an endemic gypsophile of semi-arid Spain. Journal of Ecology 87: 290-302.

418 Fowler, N. 1986. The role of competition in plant communities in arid and semiarid regions. Annual Review of Ecology and Systematics 17: 89-110.

420 Golle, D.P., Reiniger, L.R.S., Curti, A.R., Hanauer, J.G., Waldow, D.A.G. 2010. Alternative substrates and pre-germinative treatments in the in vitro germination of Pinus taeda L. seeds. Revista Árvore 34: 39-48.

Jacobs, D.F., Salifu, K.F., Seifert, J.R. 2005. Relative contribution of initial root and shoot morphology in predicting field performance of hardwood seedlings. New Forests 30: 235-251.

Jiménez, M.N., Pinto, J.R., Ripoll, M.A., Sánchez-Miranda, A., Navarro, F.B. 2014. Restoring silvopastures with oak saplings: effects of mulch and diameter class on survival, growth, and annual leaf-nutrient patterns. Agroforestry Systems 88: 935946.

Kormanik, P.P. 1986. Lateral root morphology as an expression of sweetgum seedling quality. Forest Science 32: 595-604.

Martínez-Hernández, F., Medina-Cazorla, J.M., Mendoza-Fernández, A, Pérez-García, F.J., Sánchez-Gómez, P., Garrido-Becerra, J.A., Gil, C., Mota, J.F. 2009. Preliminary essay on the chorology of the Iberian gypsicolous flora: rarity and richness of the gypsum outcrops. Acta Botanica Gallica 156: 9-18.

Matesanz, S., Valladares, F. 2007. Improving revegetation of gypsum slopes is not a simple matter of adding native species: insights from a multispecies experiment. Ecological Engineering 30: 67-77.

440 Matesanz, S., Valladares, F., Tena, D., Costa-Tenorio, M., Bote, D. 2006. Early Dynamics of Plant Communities on Revegetated Motorway Slopes from Southern Spain: Is Hydroseeding Always Needed? Restoration Ecology 14: 297-307.

Meyer, S.E. 1986. The ecology of gypsophile endemism in the eastern Mojave Desert. Ecology 67: 1303-1313.

Mota, J.F., Martínez-Hernández, F., Guirado, J.S. (Eds.). 2011. Diversidad Vegetal de las Yeseras Ibéricas. El reto de los archipiélagos edáficos para la biología de la conservación. ADIF-Mediterráneo Asesores Consultores, Almería. Spain.

448 Mota, J.F., Sola, A.J., Dana, D.E., Jiménez-Sánchez, M.L. 2003. Plant succession in abandoned gypsum quarries. Phytocoenologia 33: 13-28. 
450 Mota, J.F., Sola, A.J., Jiménez-Sánchez, M.L., Pérez-García, F.J., Merlo, M.E. 2004. Gypsicolous flora, conservation and restoration of quarries in the southeast of the Iberian Peninsula. Biodiversity and Conservation 13: 1797-1808.

Oliet, J.A., Planelles, R., Artero, F., Valverde, R., Jacobs, D.F., Segura, M.L. 2009. Field performance of Pinus halepensis planted in Mediterranean arid conditions: relative influence of seedling morphology and mineral nutrition. New Forests 37: 313-331.

Palacio, S., Aitkenhead, M., Escudero, A., Montserrat-Martı, G., Maestro, M., Robertson, A.H.J.. 2014. Gypsophile Chemistry Unveiled: Fourier Transform Infrared (FTIR) Spectroscopy Provides New Insight into Plant Adaptations to Gypsum Soils. Plos One 9(9):e107285.

Palacio, S., Escudero, A., Montserrat-Martí, G., Maestro, M., Milla, R., Albert, M.J. 2007. Plants living on gypsum: beyond the specialist model. Annals of Botany 99: 333-343.

464 Parsons, R.F. 1976. Gypsophily in plants: a review. American Midland Naturalist 96: 120.

466 Pollock, B.M., Roos, E.E. 1972. Seed and seedling vigor. In Kozlowsky T.T. (Ed.) Seed biology: Importance, Development and Germination. Vol 1. Academic Press, Inc.,

Pueyo, Y., Alados, C.L. 2007. Effects of fragmentation, abiotic factors and land use on vegetation recovery in a semi-arid Mediterranean area. Basic and Applied Ecology 8: 158-170.

472 Pulido-Bosch, A., Calaforra, J.M., Pulido-Leboeuf, P., Torres-García, S. 2004. Impact of quarrying gypsum in a semidesert karstic area (Sorbas, SE Spain).

$474 \quad$ Environmental Geology 46: 583-590.

Renou-Wilson, F., Keane, M., Farrell, E.P. 2008. Effect of planting stocktype and cultivation treatment on the establishment of Norway spruce on cutaway peatlands. New Forests 36: 307-330.

478 Ritchie, G.A., Landis, T.D., Dumroese, R.K.; Haase, D.L. 2010. Chapter 2 Assessing plant quality, in Landis, T.D.; Dumroese, R.K.; Haase, D.L. The Container Tree Nursery Manual. Volume 7, Seedling Processing, Storage, and Outplanting. Agric. Handbk. 674. Washington, DC: U.S. Department of Agriculture Forest Service.

Sharma, K.D., Kumar, S., Gough, L.P., 2001. Rehabilitation of gypsum mined-lands in the Indian Desert. Arid Land Research Management 15: 61-76. 
Sosa, V., De-Nova, J. A. 2012. Endemic angiosperm lineages in México, hotspots for 486 conservation. Acta Botanica Mexicana 100: 293-315.

Therneau, T. 2013. A Package for Survival Analysis in S. R package version 2.37-4. 488 http://CRAN.R-project.org/package=survival

Wilson, B.C., Jacobs, D.F. 2006. Quality assessment of temperate zone deciduous 490 hardwood seedlings. New Forests 31: 417-433. 